\title{
Masculinidades de seminaristas: la masculinidad religiosa y la masculinidad clerical
}

\author{
Mariana Badillo Bárcenas* \\ María del Pilar Alberti Manzanares \\ COLEGIO DE POSTGRADUADOS
}

Este estudio aborda la formación sacerdotal y la manera en que diversos factores se entretejen y dan como resultado dos masculinidades en relación con el entorno rural del Municipio de Texcoco, Estado de México. La metodología consistió en la aplicación de diversos instrumentos de los cuales se obtuvieron datos cuantitativos y cualitativos. Con base en lo anterior se propusieron dos conceptos de masculinidad que son: 1) masculinidad religiosa, características de los varones que eligen el sacerdocio; y 2) masculinidad clerical, características de los varones que se encuentran en la formación sacerdotal.

(Masculinidad religiosa, masculinidad clerical, género, formación sacerdotal, sociedad rural)

\section{INTRODUCCIÓN}

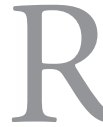

ealizar una investigación en el clero ha sido un reto constante debido al gran hermetismo que impera en la Iglesia católica; sin embargo lo que aquí se expone es un logro que pretende contribuir a la exploración de una de las formas a través de las cuales se ha estructurado el ejercicio de la masculinidad.

La devoción religiosa existente en zonas rurales es determinante para la conformación de una identidad. Los jóvenes suelen participar en actividades religiosas desde temprana edad motivados principalmente por sus madres quienes pretenden para sus hijos una mejor educación. Inician involucrándose como acólitos, van perci-

*marianabb@colpos.mx palberti@colpos.mx. 
biendo la figura sacerdotal como un modelo de masculinidad por seguir y cuando deciden formarse como sacerdotes tienen un perfil que les hace tomar tal decisión, una masculinidad (masculinidad religiosa) que posteriormente se transformará durante el proceso de convertirse en sacerdotes (masculinidad clerical).

El presente artículo se desprende de una investigación que plantea la importancia de conocer las razones que motivan a los jóvenes de las comunidades rurales para elegir el sacerdocio como opción de vida; analizar si estas razones caracterizan una masculinidad; y, entonces, evaluar si la formación sacerdotal -que implica un servicio pastoral en comunidades rurales colabora-, y de qué manera, en conformar una nueva identidad masculina.

Las preguntas que guían la investigación son: 1) ¿Qué características tienen los jóvenes que ingresan a la formación sacerdotal?; 2) ¿Qué características tiene la masculinidad de los seminaristas? El universo de estudio fue el Seminario Mayor de Texcoco ubicado en el poblado de Tulantongo en el Municipio de Texcoco, Estado de México. Los informantes fueron: 39 seminaristas, 3 sacerdotes formadores del seminario, 3 sacerdotes párrocos, 6 mujeres y 6 hombres de las comunidades de San Francisco Mazapa, ubicada en el Municipio de Teotihuacan, Municipio de Acolman y Ecatzigo, Estado de México. Para acceder a la población participante menciona$\mathrm{da}$, se obtuvo el permiso del equipo formador (rector, director académico, director espiritual, y todos los asesores de distintas áreas) después de haber presentado el proyecto de investigación.

La metodología utilizada contó con la aplicación de los siguientes instrumentos: cuestionario, entrevista, test psicológico, observación participante y entrevista con las personas de las comunidades donde hacen su servicio pastoral los seminaristas.

El artículo ofrece un sustento teórico de la masculinidad y posteriormente se hace un análisis de los hallazgos encontrados en las áreas exploradas con los instrumentos aplicados a los seminaristas, las observaciones y entrevistas realizadas a personas de la comunidad para obtener características comunes y obtener un perfil con el que se conceptualizan las dos masculinidades propuestas. 


\section{DEFINICIONES DE LA MASCULINIDAD}

Definir la masculinidad no ha sido una tarea fácil, pues, implica plantearse toda una gama de factores que influyen en la construcción del concepto. En la literatura, diversos autores han hecho el esfuerzo de definir masculinidad sobre la base de distintas interpretaciones. Para Connell (2003) "todas las sociedades tienen explicaciones culturales del género, pero no todas tienen el concepto de masculinidad" (Connell 2003, 103). Este término, afirma el autor, actualmente presume que el comportamiento de cada individuo es el resultado del tipo de persona que se es. De esta manera, un sujeto con características de personalidad propias de un hombre es masculino; así mismo, el autor afirma que el concepto de masculinidad es inherentemente relacional, pues la masculinidad no puede existir si no es en relación con la feminidad.

Para conocer algunos de los intentos por definir la masculinidad, Connell (2003) muestra cuatro puntos teóricos de partida:

a) Definiciones esencialistas: se centran en la esencia de lo que es masculino y basan su explicación en la vida de los hombres en ella. La afirmación de las definiciones esencialistas es que existe una base esencial universal de la masculinidad.

b) Definiciones positivistas: este enfoque define la masculinidad como: "lo que los hombres son en realidad" (Conell 2003, 105). La definición es la base del análisis etnográfico que describe el patrón de vida de los hombres en alguna cultura y a esto se le llama patrón de masculinidad. Connell seńala tres problemas. Primero, que de acuerdo con la epistemología moderna, no puede existir una descripción sin un punto de vista. Las descripciones que se hacen en este tipo de definiciones se realizan conforme a suposiciones que se tienen de lo que es femenino o masculino. Segundo, que para hacer una lista de las actividades de hombres y mujeres, se necesita catalogar primeramente a las personas en actividades de "hombres" o actividades de "mujeres". Y el tercer problema es que definir la masculinidad como "lo que los hombres son empíricamente" no considera que algunas veces se les llama a las mujeres "masculinas" y a los hombres "femeninos"; así mismo, tampoco se podrían explicar las acciones que se 
llaman actitudes "masculinas" o actitudes "femeninas" sin que sea importante quien las ejecute. Por lo tanto, las palabras masculino y femenino van más lejos de la diferencia sexual, no se puede limitar a hablar de lo que es "de los hombres" y de lo que es "de las mujeres".

c) Definiciones normativas: en las definiciones normativas se reconocen las diferencias y para ello la principal norma es: la masculinidad es lo que los hombres deben ser; lo que podría dar pie a que distintos hombres no se ajusten a las normas produciéndose paradojas, pues en el caso de que determinado grupo de varones no se ajusten, se arriesgan a que no pertenezcan a la masculinidad tradicional.

d) Definiciones semióticas: las definiciones de estas aproximaciones definen la masculinidad mediante un sistema de diferencias simbólicas en las que se contrastan los espacios masculinos y femeninos. Es entonces que se define la masculinidad como la no feminidad. Para el autor esta definición es muy útil para el análisis cultural, sin embargo, tiene un alcance limitado, pues,

para poder manejar el amplio rango de cuestiones relacionadas con la masculinidad necesitamos formas para referirnos a otro tipo de relaciones: a las que se dan en los ámbitos de la producción y el consumo; en ámbitos de las instituciones y el medio ambiente natural; en ámbitos de luchas sociales y militares, ámbitos todos que están ligados al género (Connell 1995, 108).

Por lo tanto el autor define la masculinidad como "un lugar en las relaciones de género, en las prácticas a través de las cuales los hombres y las mujeres ocupan ese espacio en el género, y en los efectos de dichas prácticas en la experiencia corporal, la personalidad y la cultura" (Connell 1995, 109).

Una definición que aborda más contextos es la que hace Michael Kimmel (1997), el cual considera la masculinidad como un conjunto de significados que se han modificado con el tiempo que se construyen mediante la relación con el mismo hombre, con otros hombres y con todos y todas las demás, por lo tanto la masculinidad tiene historia. Kimmel confirma que la masculinidad no proviene de la estructura biológica, sino que se crea en la cultura y que puede 
tener distintos significados según el momento y el contexto cultural; y que la forma en la que un hombre sepa el significado de lo que es ser hombre en su cultura es cuando su propia definición de hombría se opone a otras definiciones provenientes de minorías raciales, sexuales y de las mujeres en especial.

En la construcción de la conceptualización de masculinidad Kimmel retoma las palabras del psicólogo Robert Brannon (1976), quien resume lo que es la masculinidad en cuatro frases que mide la masculinidad. Las cuatro reglas son las siguientes:

1. "Nada con asuntos de mujeres" Uno no debe hacer nunca algo que sugiera feminidad. La masculinidad es el repudio implacable de lo femenino.

2. “Sea el timón principal!” La masculinidad se mide por el poder, el éxito, la riqueza y la posición social. Como lo afirma el dicho común: "El que al terminar tiene la mayoría de las piezas, gana".

3. “Sea fuerte como un roble!” La masculinidad depende de permanecer calmado y confiable en crisis, con las emociones bajo control. De hecho, la prueba de que se es un hombre consiste en no mostrar nunca emociones. Los muchachos no lloran.

4. “Mándelos al infierno!” "Exude un aura de osadía varonil y agresividad. Consígalo, arriésguese” (Kimmel 1997, 51).

Kimmel (1999) explica que las reglas anteriores habrán de cumplirse todo el tiempo, de lo contrario las consecuencias serán sentir confusión y dolor.

Por otra parte, Kaufman (1997) considera el poder como un elemento central de la masculinidad. Debido a que todas las sociedades son dominadas por los hombres, los hombres interiorizan este poder cuando desarrollan su personalidad, y la fuente de ese poder es la misma sociedad, pero los hombres aprenden a ejercer el poder como propio. Kaufman señala sin embargo, que el privilegio del poder tiene un precio: el dolor (por eliminar emociones, mantener un buen desempeño y por suprimir necesidades). Aclara,

no existe una masculinidad única, ni experiencia única de ser hombre. La experiencia de distintos hombres, su poder y privilegio real en el mundo, se basa en una variedad de posiciones y relaciones sociales. El poder social 
de un blanco pobre es diferente del de uno rico, el de un negro de clase obrera del de un blanco de la misma clase, el de un homosexual del de un bisexual o un heterosexual, [...] Los hombres generalmente tienen privilegios y poder relativo sobre mujeres en el mismo grupo, pero en la sociedad en conjunto las cosas no siempre son tan claras (Kauffman 1997,74)

Por lo tanto, para este autor la masculinidad se experimenta de distinta manera por diferentes hombres, el poder con el que cuentan es relativo y, en consecuencia, no existe una masculinidad única.

En el sentido de que la masculinidad tiene distintos significados según diversos factores, Huerta (1999) conceptualiza la masculinidad de la siguiente manera:

entiendo la masculinidad como un conjunto de prácticas sociales, culturales, sociales e históricas mediante las cuales, los hombres, en tiempos y espacios específicos somos configurados y nos configuramos genéricamente y a partir de lo cual nos reconocemos y somos reconocidos como hombres pertenecientes a contextos y realidades con diversidades culturales, clasistas, étnicas, lingüísticas, etarias, sexuales, laborales, territoriales (Huerta 1999, 50).

De esta manera, el autor reafirma que la masculinidad es un proceso sociocultural histórico, considerando en su concepto aspectos relevantes para su construcción y, en relación con esto, creo que la religión es otra "diversidad" muy importante por considerar en estas prácticas sociales, culturales, sociales e históricas.

Otra conceptualización es la que hace Ramírez (2006), quien menciona una serie de aspectos acerca de la masculinidad de acuerdo a su interés en el estudio de la violencia masculina. Para Ramírez "La masculinidad es una red de relaciones complejas de interconexión múltiple y nunca una relación lineal de dependencia entre la estructura social y el objeto sexuado" (Ramírez 2006, 53).

Difiriendo de los autores antes mencionados, Ana Amuchástegui (2006) menciona a Clatterbaugh (1998) quien afirma que el uso del término de "masculinidad" es errático y diverso, y por ello se inclina al uso con cautela de los conceptos masculinidad o masculinidades. Amuchástegui menciona que para este autor "el concepto 
de masculinidad(es) implica la existencia de una o más entidades discretas que agrupan una serie de características (sean actitudes, comportamientos o ideas) observables en ciertas personas o grupos" (Amuchástegui 2006, 172).

En consecuencia del análisis que hace Amuchástegui acerca de las afirmaciones de Clatterbaugh, la autora sugiere que la manera de formarnos una idea de masculinidad particular es a partir de determinados grupos, pero plantea una paradoja: ¿cómo podemos identificar a un grupo sin tener la idea de masculinidad?

De acuerdo con las definiciones que se han hecho de la masculinidad, Amuchástegui afirma que, a pesar de los esfuerzos por hablar de "masculinidades" diversificándola y haciéndola plural, se ha estado construyendo una contradicción debido a que la masculinidad tiene características cultural e históricamente modificables. Debido a lo anterior, la autora indica la necesidad de analizar el problema y la complejidad del concepto de masculinidad, y propone trabajar en el concepto de género para referirse a los hombres o a lo masculino siempre y cuando se tome de referencia el hecho de que los hombres o lo masculino se reconozcan como una construcción cultural. De esta manera la autora hace énfasis en que el análisis de género se debe utilizar como una categoría relacional, debido a que su principal función es la apreciación de diferencias que incluyen jerarquías entre los términos masculino y femenino, mujeres y hombres, masculinidad y feminidad.

Amuchástegui propone el término "construcción social de la masculinidad" para referirse a un conjunto de discursos y prácticas sociales que intentan definir el término "masculino" del género dentro de la configuración histórica particular, si bien hay que reconocer que hay hombres que no se "ajustan" a tal configuración.

Para concluir, Amuchástegui pone énfasis en la comprensión de lo subjetivo del género. Sugiere entender la masculinidad como "un proceso social y no como un conjunto de atributos organizados en una entidad discernible" (Amuchástegui 2006, 178).

Hacemos notar la diversidad de posturas para definir la masculinidad y sus problemas epistemológicos. De esta manera coincidimos con Hernández al explicar que "existen desfases conceptuales 
para hablar de identidad masculina, masculinidad y masculinidades" (Hernández 2008, 231). Sin embargo, consideramos que la tipificación ayuda a entender la construcción de las masculinidades en el contexto rural que aquí se expondrán.

\section{Algunas masculinidades}

En lo que respecta a las relaciones entre las masculinidades Connell (2003) plantea que es necesario reconocer que éstas se derivan de distintas masculinidades que no deben ser consideradas como fijas, pues son relativas y flexibles según su contexto; aún así propone la siguiente tipología de masculinidades:

a) Hegemónica: aquella que siempre ocupa la posición dominante de los hombres y que asegura la subordinación de las mujeres; lo cual no considera necesariamente únicamente el poder monetario, político u otro; ocupa exitosamente su posición de autoridad.

b) Subordinada: al existir una masculinidad hegemónica dominante culturalmente en la sociedad, existe en consecuencia una masculinidad subordinada. El predominio de la heterosexualidad deja en subordinación a los hombres homosexuales por contener aquello que la masculinidad hegemónica rechaza y por el aspecto femenino que también se encuentra en subordinación; por lo tanto, la masculinidad subordinada también refiere al conjunto de características asociadas con la feminidad que algunos hombres se adjudican en su forma de vivir.

c) Cómplice: es la que tiene provecho del sistema patriarcal y de la subordinación de las mujeres sin los compromisos o exigencias de la masculinidad hegemónica.

d) Marginada: surge como consecuencia de las relaciones no sólo de género, sino con las estructuras de clases y razas. La marginación, explica Connell, será relativa a la forma en que la masculinidad hegemónica ejerza su autoridad en el grupo que domina. Los varones pertenecientes a grupos étnicos son un ejemplo de las masculinidades marginadas. Es así como según el autor, la manera en que se construye la masculinidad, se basa en el tipo de relaciones que se establece con distintas personas de acuerdo a un contexto distinto, 
sin embargo, menciona también que la masculinidad tiene un proceso y en este proceso es en donde se determinan ciertas actitudes que van reafirmando la masculinidad.

Kimmel (1998) analiza la manera en que se crean las masculinidades y expresa que ninguna se aprecia de la misma manera, pues quien lo determina es la sociedad; sin embargo, explica que existe una masculinidad en la cual se evalúan y miden las demás masculinidades: "Dentro de la cultura dominante, la masculinidad que define a los blancos, de clase media, adultos jóvenes heterosexuales, es el modelo que establece los estándares para los otros hombres" (Kimmel 1997, 50). A esta masculinidad el autor la llama: "masculinidad hegemónica” basándose en estudios que realiza en Estados Unidos como país hegemónico. Para precisar más esta masculinidad, Kimmel hace referencia a Irving Goffman que dice que sólo existe una masculinidad ideal en Estados Unidos: el hombre joven, casado, blanco, urbano, del norte, heterosexual, protestante, padre, con educación universitaria, empleado de tiempo completo, buena complexión física, peso y estatura y un récord deportivo reciente. De tal manera que el hombre que no cumpla con las características de la masculinidad hegemónica, se percibirá, asimismo, según Kimmel, como devaluado, incompleto e inferior; lo que según el autor, tendrá como consecuencia psicológica el machismo (Kimmel 1999, 8).

Un autor, Cazés (1995), que hace énfasis en la manera en que se organiza la sociedad, considera que ésta basa su organización en acuerdo con los géneros y lo llama "organización genérica de las sociedades”, asimismo, dice que esta organización genérica es el resultado de las atribuciones que definen de manera distinta a hombres y a mujeres.

Cazés considera muy importante la forma en que las instituciones jurídicas y consuetudinarias se convierten en los espacios que definen y van conformando aquello que le corresponde a cada género; explica que estos atributos no se mantienen durante toda la vida, sino sólo en algunas etapas determinadas por la edad, sexo, clase, etnia, religión y nación.

Con esta explicación Cazés define los siguientes atributos masculinos: capacidad de mandar y organizar; inteligencia tanto abs- 
tracta como concreta; toma de decisiones sobre aspectos familiares; disposición de propiedades; ejercicio del poder público, militar, civil, donde defina las reglas tradicionales y jurídicas; definición de pensamiento, creencias, interpretación de la historia, educación y moral; elaboración sistemática del pensamiento, conocimiento y mitos; difusión de hechos sociales y las verdades oficiales.

Para Cazés (1995), estos atributos masculinos tienen como consecuencia que a los hombres les pertenezca: la creatividad y poderes de dominio; la racionalidad y la violencia; el manejo de otros y de la vida de éstos y las propias; la creación y manejo de instituciones; la invención y conducción de ritos con que se establece la comunicación y forman la identidad con los demás. Según Cazés estos atributos en conjunto dan como resultado una masculinidad patriarcal.

Partiendo de la concepción de masculinidad hegemónica que hace Connell (1995), donde ésta mantiene el poder que el sistema patriarcal le confiere, coincidimos con los autores Gustavo Briceńo B. y Edgar Chacón M. (2001), que caracterizan a la masculinidad patriarcal como aquella que es una conducta y una estructura ideológica donde se decide y modela esa misma conducta basada en atributos, valores, funciones y conductas que se suponen esenciales al varón en una cultura determinada. Así, los autores crean el perfil de la masculinidad patriarcal, la cual cumple con los siguientes mandatos o roles masculinos:

a) Todopoderoso: se refiere a que el hombre debe ser muy trabajador, buen proveedor en casa, soluciona bien todos los problemas, asume riesgos, es agresivo y asertivo. No es dependiente, logra una sexualidad separada del afecto.

b) Insensible e inexpresivo: se refiere a la inexpresividad de las emociones o sentimientos; pues el hombre debe ser fuerte, callado y duro; no pide nunca ayuda aunque ponga en riesgo su salud física o emocional.

c) Fuerte: especialmente la fortaleza física es otro mandato masculino que se refuerza a temprana edad con juegos, deportes y otras habilidades; o bien, fuertes apretones de manos o de palmadas en la espalda. Se refuerza igualmente la alta tolerancia al dolor. 
d) Preńador: este mandato tiene especial relevancia social e implica la garantía de posesiones materiales, prestigio y mostrar sobre todo, que puede embarazar a una mujer y en algunos casos, mientras más hijos, más hombre se es.

e) Heterosexualidad obligatoria: implica condenar la homosexualidad como orientación sexual y el castigo a rasgos homosexuales.

f) Mujeriego: el mandato de ser mujeriego también es considerado como una obligación puesto que se reconoce como más hombre a aquel que más mujeres tenga, pasando por alto las implicaciones emocionales que implique para la mujer y para el mismo hombre.

g) Tomador o bebedor: es reconocido como más hombre aquel que toma más y "aguanta" más, y por lo tanto, quien menos toma es el más débil lo cual se opone a la fortaleza necesaria para ser hombre.

h) Omnisapiente o el "sabelotodo": es la exigencia de que el hombre debe saber de todo y tener la razón en lo que dice en cualquier tema; es muy importante que no se quede callado, pues denotaría poca experiencia y poco reconocimiento.

i) Referente de la humanidad: refiere a cuando los hombres se convierten en los representantes de los países, pueblos y hogares; así cada hombre tiene que representar a los demás, es el ejemplar elegido.

Por otro lado, hay una masculinidad que ha sido poco estudiada que es el modelo de masculinidad de Jesús de Nazaret, como modelo religioso. Hay quienes hablan de la masculinidad de Cristo con la finalidad de que ésta sirva como modelo para construir nuevas masculinidades, pues consideran que la manera de ser varón de Cristo ha dejado un legado de igualdad y equidad con mujeres. Ceballos (2007) explica la innovadora actitud igualitaria de Jesús en un contexto patriarcal. La autora apunta que la literatura bíblica es androcéntrica y que aparece en un contexto patriarcal que también se sustenta con ésta. Tras hacer una revisión de la posición de la mujer en el judaísmo en el tiempo de Jesús, se basa en el cuarto evangelio ${ }^{1}$ para citar lo siguiente: "Jesús supera todos los prejuicios y tabúes, raciales o sexuales, y se muestra un hombre extraordinariamente libre”. La frase que cita Ceballos explica que la forma de ser de Jesús

${ }^{1}$ J. M. Martín Moreno, Cuarto Evangelio. El diálogo con la samaritana, Inédito. 
era opuesta totalmente al sistema patriarcal imperante de su contexto y que al reintegrar a la mujer a la vida pública, liberándola del servilismo, tratándola además con naturalidad, respeto y cariño, Jesús fue un revolucionario que "libera" a las mujeres dando el ejemplo por seguir para otros hombres y para otras relaciones de género. Por su parte Reyes (2004) incluye en su análisis la manera de relacionarse que el profeta tenía con niñas, niños y con otros varones; de esta forma propone el modelo de la masculinidad de Jesús y lo llama "masculinidad humana y humanizadora". El autor explica este modelo con base en el estudio de los Evangelios que muestran que Jesús no sólo liberó a las mujeres mostrando que el trato con éstas habría de ser justo y equitativo, sino que también trata a niños y a niñas con cercanía, afectividad y con el respeto que merecían a diferencia de otros hombres de su tiempo; muestra también un trato equitativo con personas de distinta condición social, sexual o de distintas etnias. Y con respecto a Jesús y su relación con otros hombres y la masculinidad impuesta, el autor explica que vivía libremente y humanamente, de manera que cumplía con las costumbres propias de los varones de su pueblo como era participar en fiestas religiosas, presidir en las comidas de grupo, aceptar invitaciones a comer de otros varones, entre otras; sin embargo, modificando siempre las situaciones o costumbres que implicaran la exclusión de otras personas (mujeres, niños, pobres, ancianos, enfermos, esclavos, entre otras). Estos comportamientos mostrarían un hombre diferente que invita a que todas las personas vivan de manera justa, de manera humana y que transmitan esto a quienes puedan para humanizarlos. Otra voz que coincide con lo anterior es la de Leonardo Boff (1988), un reconocido teórico de la Teología de la Liberación, que desarrolló estudios de Cristología. Este autor afirma que Jesús desarrolló su dimensión femenina de compasión y ternura para los pobres y marginados "no es machista ni rígido, ni es violento [...] es muy tierno y compasivo cuando encuentra a las personas en su debilidad, en su situación humana y ahí yo veo que aparece la dimensión femenina de Jesús" (Tamez 1988, 111).

En otro sentido, se analiza la respuesta que han tenido los varones ante los cambios que el feminismo ha impulsado para generar 
nuevas masculinidades que se aparten de la masculinidad patriarcal. Un autor que se ocupa de esto es Luis Bonino (2003), que hace una clasificación detallada de las distintas respuestas masculinas en Europa frente al cambio femenino y frente al feminismo. El autor agrupa a los hombres en tres categorías que son:

1. Los contrarios a los cambios de las mujeres: con mayor frecuencia son varones mayores de 55 ańos, con estudios medios y relacionados con mujeres que asumen roles tradicionales (el hogar), desempleados o sin un trabajo altamente calificado y que viven en comunidad pequeña. Con un manejo de discurso androcéntrico, paternalista y machista donde niegan la desigualdad entre hombres y mujeres. Comprenden la lucha de las mujeres como un intento de dominar a los varones o para romper el orden social, mas no como reivindicación de igualdad.

2. Los favorables a los cambios de las mujeres: generalmente son hombres jóvenes, con estudios superiores, solteros, sin hijos, que se relacionan con mujeres que trabajan en ámbitos públicos y que viven en urbes. Se cuestionan su rol masculino y el de sus compañeros; así mismo tienen apertura para convivir igualitariamente; casi no encuentran modelos de masculinidad que les resulten atractivos. En esta misma categoría se encuentran los "utilitarios o igualitarios unidireccionales" porque se benefician de los cambios de la mujer sin ofrecer nada a cambio, aceptan que la mujer asuma "funciones masculinas". La mayoría de los varones utilitarios, cree que la lucha por la igualdad sólo la deben hacer las mujeres.

3. Los ambivalentes: varones entre 35 y 55 ańos que viven en pareja con mujeres que laboran en el ámbito público o divorciados, con hijos y son ambivalentes porque sólo en algunos asuntos se encuentran a favor de los cambios de las mujeres (dinero) y en otros no (doméstico). Suelen sentirse desorientados ante los cambios de las mujeres a quienes ya no pueden o desean controlar, por lo tanto se perciben debilitados y buscan adecuarse.

Bonino hace mención de que todos estos varones de alguna manera son conscientes del cambio de las mujeres y que la violencia es una manera de reaccionar ante éste; van aceptando que la mujer vaya entrando al ámbito público, pero ellos se siguen resistiendo a 
entrar al ámbito doméstico donde sólo lo hacen como "ayudantes" y precisamente en este ámbito es donde se encuentra, según el autor, el "núcleo de la desigualdad".

Bonino también explica los factores por los cuales los varones se resisten al cambio. Entre éstos, menciona que un valor en que se afirma la autoestima masculina en varones sometidos a la masculinidad hegemónica es la superioridad y autoridad con respecto a las mujeres, pues ejerciendo este poder el varón cumple con "el ideal de masculinidad". Este poder le da reconocimiento ante sí mismo y ante otros manteniendo la autoestima alta; pero si esto se ve impedido con la igualdad, no se soportará la herida a la autoestima sobre todo si no hay soportes alternativos. Otro factor es la percepción masculina de la igualdad como amenaza a la identidad masculina porque la igualdad se asocia con la feminización. Por ello si las mujeres comienzan a sentir que tienen derechos, el varón sentirá que pierde no sólo poder, sino también su identidad por no cumplir el mandato masculino de tener el poder. Otros factores que obstaculizan el camino hacia la igualdad son los temores hacia lo nuevo, la falta de modelos masculinos no tradicionales y el miedo a los cambios.

Además de estos autores, también han hecho aportaciones relevantes otros como Pierre Bourdieu (2004), quien en "El baile de los solteros" analiza desde la sociología, la soltería de los varones y su celibato en un sistema patriarcal dentro de una comunidad rural de Francia. Para el caso de Colombia, Brusco (1995) realiza una investigación para conocer las diferencias de actitudes de hombres y mujeres al cambiar de religión, colocando a las mujeres en "una posición mejor" debido a que los hombres transforman su masculinidad patriarcal para obedecer los mandatos religiosos (evangelismo protestante) opuestos a los mandatos de la masculinidad tradicional (alcoholizarse, tener relaciones extramaritales, hacer gastos innecesarios, entre otros).

La revisión de las teorías sobre masculinidades y la construcción de éstas permite conocer distintos puntos de vista para la comprensión de la relatividad que implica la conceptualización y el estudio de las mismas. En este artículo consideramos que no existe una masculinidad, sino diversas, y por ello se proponen dos perfiles basados 
en los datos obtenidos en el trabajo de campo y la revisión teórica anterior relacionados con algunos candidatos al sacerdocio en la región de Texcoco.

\section{LA CONSTRUCCIÓN DE DOS MASCULINIDADES}

La definición de masculinidad, como se dio a conocer en el marco teórico, es compleja. A medida que el conocimiento ha avanzado, hoy queda claro que no existe una sola masculinidad, sino masculinidades; y aquello que hace la diferencia entre una masculinidad y otra son los diversos factores que las conforman como la cultura, educación, momento histórico, etnia, edad, clase social y otras.

Estudios etnohistóricos muestran la manera en que la religión ha influido notablemente en las actividades de las comunidades (rurales sobre todo) desde la época prehispánica; de tal forma que el universo de estudio de la presente investigación es relevante por ser un entorno rural con una historia religiosa importante desde tiempos prehispánicos (Teotihuacán) hasta ser cuna de sacerdotes debido a que en este lugar se encuentra uno de los seminarios diocesanos más importante del Estado de México. En este sentido, el papel de la figura sacerdotal ha sido trascendental en la construcción de las masculinidades y de las relaciones de género en las comunidades rurales.

Los instrumentos aplicados a jóvenes estudiantes del seminario, el trabajo de observación participante y las entrevistas hechas a personas de las comunidades donde dan servicio pastoral los alumnos, permiten caracterizar la masculinidad de los seminaristas ya sea como varones motivados a formarse como sacerdotes o bien, como candidatos al sacerdocio, específicamente como seminaristas. Así se encontró que los varones que eligen el sacerdocio, presentan ciertas características que conforman una masculinidad que llamamos masculinidad religiosa, y una vez que inician su formación sacerdotal, la identidad masculina se modifica debido principalmente al poder que les confiere la Iglesia y la feligresía: la masculinidad clerical. Esta última es una modificación del tipo de masculinidad anteriormente mencionada, que se determina cuando los seminaristas son orientados en los valores de la dinámica pedagógica del seminario. 
Consecuentemente se proponen dos conceptos de masculinidad que a continuación se explican.

\section{Masculinidad religiosa}

Es importante conocer las características sociales, culturales, económicas y psicológicas de los jóvenes seminaristas para entender el concepto de masculinidad religiosa. Se tomaron en cuenta las siguientes áreas que se reportan a continuación con los datos obtenidos en el área cuantitativa y cualitativa.

a) Edad: la edad promedio que reportaron los jóvenes entrevistados cuando se interesaron en la formación sacerdotal o cuando pensaron por primera vez en ser sacerdotes es de 14.7 ańos, ya que las edades oscilan entre los 8 y 22 años; a diferencia de la edad promedio que tuvieron los seminaristas cuando ingresaron al seminario que fue de 18.2 con edades entre 14 y 23 ańos. De esta manera observamos que son varones muy jóvenes, la mayoría en plena adolescencia, quienes sienten interés por ser sacerdotes y lo siguen teniendo cuando deciden ingresar al seminario.

b) Lugar de procedencia: en los datos cuantitativos a partir del cuestionario aplicado se explica que la mayoría vive en comunidades de la diócesis de Texcoco (el territorio a cargo de un obispo), sin embargo, algunos alumnos provienen de comunidades fuera de la diócesis. Estas comunidades son en su mayoría rurales.

c) Escolaridad: del cuestionario también se obtiene que 79.31\% de los alumnos ingresa al seminario con estudios de preparatoria, asimismo $20.68 \%$ de alumnos han estudiado licenciatura, pero la mitad no la terminó. Por lo que se entiende que estos jóvenes tienen apenas la educación media superior.

d) Contexto familiar: la mayoría de los jóvenes viven en un contexto familiar tradicional donde la madre y el padre viven juntos en matrimonio, tienen dos o más hermanos y la mitad de los seminaristas es el hijo menor o intermedio. La relación familiar es variable con los integrantes de la familia, pues se encontró tanto en el cuestionario aplicado a 29 alumnos como en el test aplicado a 10 voluntarios, que más de la mitad de los varones se encuentra en una relación conflic- 
tiva con su padre, o bien, demandan atención por parte de esta figura. Por otro lado, los mismos instrumentos muestran que casi la mayoría tiene mejor relación con su madre. El cuestionario reporta que todos tienen una buena relación con su madre y el test psicológico muestra a la madre percibida en su rol tradicional ausente de autoridad y de quien los seminaristas suelen ser más dependientes. En lo que respecta a la relación con sus hermanos, de los encuestados, $75 \%$ menciona tener una relación buena. El test psicológico muestra que 5 de 10 alumnos perciben un entorno familiar conflictivo o que les genera confusión. Se resume que los jóvenes que desean ser sacerdotes viven en un contexto familiar patriarcal donde sobresale la figura paterna como conflictiva o ausente y donde la figura materna no tiene autoridad, pero de la que muchos seminaristas son dependientes. Posiblemente la estructura familiar patriarcal influya en la percepción de un entorno familiar conflictivo.

e) Contexto religioso: de mayor importancia resulta el contexto religioso para caracterizar la masculinidad de estos varones pues los datos encontrados muestran que desde temprana edad se involucran en actividades religiosas, ya que se encuentran en un entorno familiar y comunitario con gran compromiso religioso. La figura femenina, bien sea la madre o la abuela, es la principal promotora de fomentar la religión y actividades religiosas en estos jóvenes inclusive de manera obligatoria. Casi la mitad de los seminaristas se involucraron en actividades religiosas al menos una vez por semana antes de ingresar al seminario, mientras que $31.03 \%$ de los encuestados lo hacían diariamente. Las actividades religiosas en las que se han involucrado desde temprana edad van desde la asistencia a misa dominical hasta la participación, como acólitos, en retiros espirituales juveniles, en coros de alabanza a Dios, en actividades de beneficencia a gente con mayor necesidad, participación en la organización de fiestas patronales y en pastorelas, entre otras. De manera que estos jóvenes pueden encontrar en la Iglesia su principal grupo de referencia puesto que demuestran que en este ámbito se sienten identificados con los demás asistentes varones y desarrollan gusto por las actividades. Asimismo se van sintiendo atraídos por la figura sacerdotal, la cual se convierte en el referente por seguir como modelo de masculinidad. 
f) Contexto social: los datos cuantitativos y cualitativos muestran que los varones del seminario, en su mayoría, han tenido pocas relaciones sociales; de manera que se han desenvuelto en un contexto social reducido y, por consecuencia, con poca popularidad. Todos los seminaristas afirman que su ingreso al seminario ha incrementado de manera notoria su número de amistades.

g) Contexto económico: la mayoría de los seminaristas provienen de un hogar donde el único proveedor es el padre y la madre se dedica al hogar, lo cual reduce los ingresos económicos. En mayor proporción, los padres tienen la ocupación de comerciantes, empleados y otras actividades. Aunque algunos seminaristas han laborado antes de ingresar al seminario, sus ocupaciones fueron dentro de las posibilidades que les ha dado su preparación, empleándose en actividades con remuneración económica muy escasa. Algunos seminaristas reconocen que de no ser porque el seminario ofrece la posibilidad de obtener una formación con ayudas caritativas, muchos de ellos no tendrían la posibilidad económica de continuar con sus estudios.

h) Contexto de la salud: la mayoría de estos varones no reporta ningún problema de salud grave, de hecho, $68.9 \%$ respondió que su salud era buena. Sin embargo, casi todos los alumnos entrevistados resultaron tener algún evento de mala salud como hospitalizaciones por accidentes, enfermedades, padecimientos, entre otros; resultó que algunos alumnos no creen que sea un problema de salud la obesidad o el peso bajo (situación en la que se encuentran). Por otro lado, no se reporta consumo de bebidas alcohólicas, sólo la mitad de los que respondieron el cuestionario contestan que rara vez las consumían, así mismo, la mitad no fuma y el resto lo hace ocasionalmente.

i) Contexto sexual: para este grupo de varones la sexualidad es un área de su vida poco explorada y ante la cual hay una actitud evasiva debido principalmente a una concepción de la sexualidad bajo esquemas tradicionales donde se asocia la vida sexual con el matrimonio o, bien, donde se evade por el fiel compromiso con su futura vida célibe para cumplir con la pureza que requiere el sacerdocio. Los resultados cualitativos y cuantitativos mostraron que 
aunque todos han tenido relaciones sentimentales, estas relaciones han sido pocas (máximo 4 y de escasa duración). La mayoría indicó que el tiempo máximo fue de tres años y tomaron en cuenta sus "noviazgos" de primaria (incluso preescolar); así mismo, casi la mitad de los jóvenes al ingresar al seminario no han tenido experiencias sexuales. Respecto a la orientación sexual, se encontró en los testimonios y concretamente en los test psicológicos, que hay algunos varones con orientación homosexual, la cual no manifiestan abiertamente. No se descarta la idea de que la homosexualidad, al ser considerada como antinatural desde la perspectiva religiosa, sea motivo también de la evasión de la sexualidad, pues muchos seminaristas entrevistados opinaron que la vida sexual del homosexual se debe vivir con abstinencia.

j) Contexto psicológico: al explorar el área inconsciente se obtuvo que sólo la mitad de los participantes (10 alumnos) tiene aspiraciones y expectativas claras de futuro, la otra parte tiene confusiones o pocas aspiraciones; todos tienen necesidad de reconocimiento y de logros, aunque en distinta medida, pues hubo quienes incluso tuvieron tendencias exhibicionistas y narcisistas. Casi la mitad de estos varones tiene aspiraciones muy elevadas; y por último, como un aspecto de gran relevancia para el punto de vista de género, la mayoría de estos participantes mostraron hostilidad hacia la mujer en el contexto de relaciones heterosexuales, así mismo, esta figura es percibida de manera tradicional bajo el esquema patriarcal.

k) Contexto intelectual: la intención de este contexto fue conocer el aprovechamiento escolar. Los resultados cuantitativos muestran que en su mayoría los alumnos evalúan como bueno su aprovechamiento escolar. De acuerdo con las entrevistas con los formadores, el seminario pide como condición que los alumnos que se postulan como candidatos a la formación sacerdotal tengan un promedio mínimo de 8.5 , y se deduce que la mayoría tiene la capacidad intelectual adecuada al menos para comprender lo que la formación exige.

Las características que tienen los varones motivados a ingresar al seminario permiten observar que aunque estos varones se encuentran adaptados al sistema patriarcal (por la manera en que se confor- 
ma su vida familiar, la percepción que tienen de la mujer y otras características), no tienen una masculinidad patriarcal, al menos no como la conceptualiza Cazés (1995), quien afirma que consiste en la atribución de ciertas capacidades en los varones como son la capacidad de mando, de organización, de inteligencia, de toma de decisiones familiares y de propiedades, de ejercer poder público, de definir el pensamiento y creencias de otros, de interpretar la historia, de elaborar el pensamiento y de difundir hechos y verdades oficiales; tampoco se adecua a la masculinidad patriarcal que describen Gustavo Briceño B. y Edgar Chacón (2001), que la caracteriza como aquella conducta y estructura ideológica que cumple los siguientes mandatos: ser todopoderoso, insensible o inexpresivo, ser fuerte físicamente, buen preñador, heterosexualidad obligatoria, mujeriego, tomador y bebedor, omnisapiente y ser referente de la humanidad.

De acuerdo con Connell (2003), la masculinidad de estos jóvenes se acerca más a una masculinidad subordinada ya que según el autor, sólo la masculinidad hegemónica ocupa la posición dominante de los hombres y ejerce de manera exitosa su posición de autoridad, los demás hombres quedan por lo tanto subordinados a esta masculinidad y como es visible en la descripción, estos jóvenes no cuentan con ningún tipo de poder, llámese monetario, político ni otro (al menos no fuera del seminario).

La religión como guía de vida para estos varones permea los demás contextos, la figura materna como única presencia y un padre ausente por ausencia física o emocional van construyendo su masculinidad.

$\mathrm{Al}$ seguir las normas religiosas desde temprana edad, los varones tienen un estilo de vida asociado comúnmente al rol femenino debido a que la religión regula, contiene, modera y limita muchos comportamientos masculinos patriarcales, entre ellos la ingesta de bebidas alcohólicas, el comportamiento sexual, la heterosexualidad obligada o la violencia, entre otras. En consecuencia, un varón que contiene, modera y limita sus acciones tradicionalmente definidas como masculinas, sería un "varón femenino".

El logro de que un varón tenga estas características, por otro lado, no es el resultado de una elección libre por parte de éste, sino 
por una marcada influencia de la madre principalmente, quien con otros varones jóvenes ejercen una importante autoridad para que su hijo participe en actividades religiosas.

Un niño que busca construir una identidad masculina encuentra como modelo a aquel que cubra ciertos requisitos como que le preste atención, le muestre interés, con quien tenga mayor cercanía y quien tenga poder para ser admirado, requisitos que muchos padres cumplen al estar comprometidos con su paternidad y logrando la admiración por su sola presencia física y emocional. Un padre ausente física o emocionalmente pudiera ser el modelo de masculinidad por seguir siempre y cuando no existiera otra figura de mayor impacto como lo es un sacerdote. El sacerdote se convierte en el modelo de masculinidad quizá sustituyendo los compromisos paternos, pero sobre todo con el poder de ser admirado precisamente por la característica de representar a Dios. Una vida entregada a los lineamientos religiosos se convierte en "el mejor modelo de masculinidad" por seguir debido al poder que la figura del sacerdote tiene, poder deseable para varones que, como hemos visto, perfilan más cualidades femeninas que masculinas y que, sin embargo, el poder del sacerdocio reivindica.

La masculinidad religiosa, por lo tanto, es aquella masculinidad fuertemente comprometida con la religión que valora las características del varón no patriarcal y más cercano al "varón femenino". La masculinidad religiosa contiene, modera y limita los comportamientos tradicionalmente masculinos, que no tiene poder económico, político, social u otro pero que a través de seguir el modelo de masculinidad sacerdotal (masculinidad hegemónica en el sentido de que tal poder se sobrepone al poder de otros varones, pues es el representante de Dios) consigue poder.

\section{Masculinidad clerical}

La masculinidad clerical es el resultado de la transformación de la masculinidad religiosa debido a la formación sacerdotal que inician en el seminario dirigida a ser sacerdotes.

La masculinidad clerical se caracteriza principalmente por la presencia de dos componentes: 1) Presencia de componentes aso- 
ciados con la feminidad social y 2) Presencia de componentes asociados con la masculinidad hegemónica.

Presencia de componentes asociados con la feminidad social

Los rasgos asociados con la feminidad social son el conjunto de características que tradicionalmente han sido designadas para la mujer pero que en la masculinidad clerical se adquieren de dos maneras:

a) Los factores que conforman una masculinidad religiosa ya se describieron con anterioridad, basta con sintetizar que estos rasgos asociados con la feminidad social se refieren a la contención, moderación y limitación de comportamientos tradicionalmente masculinos guiados por la religión, y la carencia de poder como otro rasgo asociado con la feminidad.

b) Los lineamientos pedagógicos que inculca el seminario:

1. El espíritu de servicio presente aún antes de la formación sacerdotal

En la exploración del proceso de admisión para los aspirantes al sacerdocio, los formadores explican las cualidades deseables en los varones que desean ingresar al seminario. Estas cualidades son diversas, sin embargo, se pone énfasis en actitudes que demuestran que quieren verdaderamente ser sacerdotes a través de la observación que se lleva a cabo en el preseminario, pero sobre todo en el curso introductorio:

es de tiempo completo vivir en el seminario; y también se les pide ciertas actitudes de servicio, de desprendimiento, de solidaridad [...] con la intención de que ellos se metan realmente a tomar una decisión en esa semana: "quiero entrar al seminario, quiero empezar como que este camino de discernimiento o de plano busco por otro lado" (Formador, Seminario Mayor de Texcoco 2008, cursivas nuestras en las citas siguientes).

Otro testimonio de un formador que subraya el énfasis en la actitud de servicio es el siguiente: 
a algunos les pedimos que vayan a ayudar a su párroco en catequesis, a otros que ayuden a cierto padre en organizar retiros para adolescentes o para jóvenes, a otros les pedimos cualquier otro servicio; es decir, todo esto es verificable sobre todo, a través de la observación; que es responsable, que dedica tiempo para preparar los temas que le tocan, que es puntual, que va transmitiendo de sí mismo su fe, su servicio a otros jóvenes; por lo contrario, si es una persona que no le gusta ir, que hace lo posible por estar el menos tiempo posible con el grupo que le toca atender, o que no se prepara, o que no lo hace con alegría; nosotros decimos: "como que no tiene ese espiritu de servicio"; se le confronta y se le dice o se le trata de ayudar a encontrar la razón del porque no surge este espiritu de servicio (Formador, Seminario Mayor de Texcoco 2008).

La actitud servicial es un requisito fundamental como cualidad para ingresar al seminario y comportamiento reforzado durante toda la formación sacerdotal.

poco antes de la ordenación, para esto podemos decir que ya han pasado 7 años, 8 años en su formación. ¿Qué se le pide?, se le pide ya un perfil estricto [...] también el que esté convencido que el sacerdocio, en donde quiera que se le pida prestar su servicio, va a ser una manera de entregarse a Dios y a la Iglesia; que no va a poner en ningún momento pretextos para no estar en cierta comunidad (Formador, Seminario Mayor de Texcoco 2008).

El "ser para”, según Marcela Lagarde (2003) (junto con el "ser de”), es una característica de la mujer que ha sido aprendida en nuestra cultura y que la mantiene en cautiverio. El servicio es considerado como parte del rol femenino, el servicio a las otras personas pertenece a la feminidad.

\section{La generosidad}

La generosidad es un aspecto que se considera necesario durante la formación, que se relaciona con el servicio. Los siguientes testimonios de formadores muestran que la generosidad es un requisito valorado durante la formación fundamental en el servicio pastoral: 
lo más fuerte que se le pide poco antes de la ordenación es su generosidad; lo que nosotros le llamamos la caridad; que sea cercano, que sea capaz de escuchar, que no sea voluble, que no impere sobre todo su carácter sino primero están los demás antes que él" (Formador del Seminario Mayor de Texcoco 2008). La generosidad, el espiritu de servicio y el ideal de querer ayudar a otras personas, esos son elementos básicos (Formador del Seminario Mayor de Texcoco 2008).

La generosidad implica una capacidad de dar, regalar, entregar incondicionalmente que es lo que se enseña a las mujeres en el contexto patriarcal para que sea dadora de servicios.

\section{Empatía: escuchar y comprender a los demás}

La capacidad de escuchar y comprender a los demás son otros aspectos muy importantes por desarrollar para que los seminaristas logren durante su servicio pastoral ser empáticos con la feligresía. "Las funciones sacerdotales requieren de escucha, de la paciencia, de la confiabilidad" (Formador del Seminario Mayor de Texcoco 2008).

De hecho la capacidad de empatía se desarrolla a través de la convivencia de los jóvenes con sus compañeros durante la formación, la cual es observada por sus formadores para dar su visto bueno al determinar si el seminarista pasa a la siguiente etapa formativa como aquí se muestra:

En lo humano que haya una coherencia entre lo que ellos están buscando de ser sacerdotes, con una modificación que vaya notándose de sus actitudes personales: que vaya siendo más paciente, más comprensivo, que de pronto se le note que va ya sabiendo escuchar, o que sepa también compartir su propia vida, etcétera (Formador del Seminario Mayor de Texcoco 2008).

La empatía se contrapone al mandato inexpresivo e insensible de la masculinidad patriarcal de Briceño y Chacón (2001) puesto que expresar emociones, y sobre todo las que indican vulnerabilidad y utilizarlas para lograr la empatía, es un comportamiento asociado al rol femenino. 


\section{La fraternidad}

La formación sacerdotal implica una convivencia comunitaria durante su proceso, por lo cual, se les motiva a vivir fraternalmente con esta comunidad de manera que sirva como entrenamiento para hacerlo extensivo a las comunidades donde harán su servicio pastoral.

aquí viven las 24 horas del día con los mismos, aprenden a vivir en comunidad en cuanto a que se interesan también por el otro [...] son compartidos, saben integrarse, saben trabajar en equipo. Yo creo que ésta es una de las características que son necesarias, que han de aprenderlas y creo que son las más notorias. Cuando terminan también se manifiestan que han aprendido (Formador del Seminario Mayor de Texcoco 2008).

Un formador explica lo que un seminarista ha aprendido en su formación:

son jovencitos que van madurando humanamente, ayudados por los formadores, [...] cuando terminan, o sea, el alumno que termina sus estudios [...] es un alumno que humanamente se le ve muy maduro, muy maduro, o sea, debidamente para ser sacerdote; también por ejemplo: que se sabe integrar, sabe convivir, es servicial, y sí, sí se nota el cambio (Formador del Seminario Mayor de Texcoco 2008).

Como la fraternidad implica entablar una relación afectuosa con quienes se relacionan y el afecto no es otra cosa que amor, esta actitud también se asocia con la feminidad puesto que mostrar amor va en oposición a la insensibilidad, inexpresividad de emociones o sentimientos que como ya revisamos, ordena la masculinidad patriarcal (Briceño y Chacón 2001).

\section{La vida casta y célibe}

Dos mandatos obligatorios de todo hombre es ser mujeriego y ser preñador (Briceño y Chacón 2001). La vida casta y célibe que fomenta el seminario se encamina sobre todo a que los sacerdotes 
tengan total pureza para entregarse de lleno a la vida espiritual y por lo tanto se requiere de la soltería y de la abstinencia sexual para lograrlo. Durante la formación se les orienta a llevar un estilo de vida célibe como la mejor opción. El siguiente testimonio es un ejemplo de este punto de vista:

Que es una norma positiva de la iglesia, que es buena, es bueno el celibato, porque ayuda a encaminar todos los esfuerzos de la vida, hacia el fin que es realizarse como sacerdote, en sus distintas formas, como ya lo mencionaba, el entregarse totalmente a Dios y a todas las personas, sin límite de tiempo, así completamente estar, el celibato da la oportunidad para no tener compromisos para poder entregarse totalmente a la comunidad, entonces siento que es bueno, muy positivo (Seminarista "5", Seminario Mayor de Texcoco 2008).

Sin embargo, fuera de la vida célibe para la formación sacerdotal, se encontró que los alumnos, por propia convicción, se han abstenido de tener relaciones sexuales, y resulta que $41.37 \%$ de los 29 seminaristas nunca han tenido experiencias sexuales. Menos de la mitad de los seminaristas entrevistados afirmaron que no llevarían una vida célibe si el celibato no fuera necesario para la formación sacerdotal.

Mira yo creo, y muy personal, por lo que quiero no es lo que diga la Iglesia, no es lo que digan los documentos, es por lo que yo estoy convencido a partir de mi vivencia es que: es indispensable, si uno quiere llegar a ser sacerdote célibe, es indispensable que se viva el celibato ya desde el seminario (Seminarista “7”, Seminario Mayor de Texcoco 2008).

Por lo tanto "preñar" para los seminaristas no es una opción y si lo fuera sería dentro del matrimonio, lo que implicaría el abandono de la formación sacerdotal. De esta manera la castidad y el celibato se convierten en requisitos necesarios asociados al rol femenino y opuestos totalmente a las características de una masculinidad patriarcal que implica tener muchas relaciones sexuales con muchas mujeres sin compromisos emocionales y así mismo tener muchos hijos para demostrar en esto la capacidad varonil (Briceño y Chacón 2001). 


\section{Actividades domésticas}

Otras actividades que se asocian a lo femenino son las del aseo; los seminaristas realizan actividades de limpieza en el seminario, las cuales, en un principio no son muy aceptadas por estar relacionadas con el rol femenino, sin embargo terminan asimilándolo y sin opción para evitarlo. Un formador explica que una de las actividades que menos les agrada a los seminaristas es el aseo: "Al principio las comunitarias, por ejemplo: la limpieza general, el trabajo en equipo, porque no lo traen, apenas como que lo están comenzando a hacer..." (Formador del Seminario Mayor de Texcoco 2008).

Un seminarista dice que las actividades del seminario que menos le agradan son las de limpieza. Con ello muestra en cierta forma el deseo de defender su hombría con el argumento de que la actividad no es por gusto, es necesaria: "Tal vez un tanto los aseos, igual y porque luego llega el aseo que no te gusta, entonces, pero bueno, lo tienes que hacer, y sería el único” (Seminarista “1”, Seminario Mayor de Texcoco 2008).

Finalmente estos componentes asociados al rol femenino, se contraponen con el desarrollo de una hegemonía que otorga la formación como a continuación se explica.

Presencia de componentes asociados con la masculinidad hegemónica

Los componentes asociados a la masculinidad hegemónica que tiene la masculinidad clerical se adquieren durante la formación sacerdotal a través de una autoridad delegada por la Iglesia, institución que además es rectora, formadora y una de las principales promotoras del sistema patriarcal. También refuerza esta masculinidad la feligresía, compuesta en su mayoría por mujeres.

\section{Hegemonía masculina única}

La masculinidad hegemónica (Connell 2003) es aquella que siempre ocupa la posición dominante de los hombres; los siguientes testimonios muestran la percepción que los mismos seminaristas 
tienen de la figura sacerdotal. Algunos testimonios resaltan la hegemonía sobre el resto de los demás hombres, porque sólo el sacerdote, es igualado con Cristo, el hijo de Dios: "Pues le digo que siempre yo lo he visto así como algo muy alto, yo lo veía así como Jesús mismo, porque es su representante; entonces la figura del sacerdote representa eso para mí, Jesús mismo" (Seminarista "1", Seminario Mayor de Texcoco 2008).

El sacerdote, como Jesús mismo en la tierra e hijo de Dios, parece tener tal posición que incluso casi pierde características humanas, además de que indudablemente el sacerdote es quien guía, es un líder, de esta manera ocupa esta posición dominante sobre hombres y mujeres:

Representa para mi otro Cristo; bueno, el representante de Cristo, por así decirlo, aquí en la tierra [...] pues Cristo pasó como un pastor que su misión de cuidando a su rebaño, que acompañar a sus ovejas, guiarlas, cuidarlas y estar al pendiente de ellas [...] yo digo: "pues antes que humano y demás (yo sé que es humano y todo), pero pues también es sacerdote", y lo que representa para mi otro Cristo aquí en la tierra (Seminarista "3", Seminario Mayor de Texcoco 2008).

Sólo el sacerdote puede encontrarse verdaderamente cerca de Dios, lo que hace una notable diferencia con el resto de hombres y mujeres:

El hecho de celebrar la eucaristía, yo siento que es el cúlmen o la finalidad del sacerdote [...] Esa es propiamente la eucaristía; la conmemoración del misterio pascual; en el que Cristo decide quedarse con nosotros de alguna manera en su cuerpo y en su sangre. Eso es lo que más me gusta del sacerdote, y hay un Salmo muy hermoso que dice: "Ni los ángeles están tan cercanos a ti como el hombre", en este caso refiriéndose así al sacerdote que es capaz, así lo creemos y yo estoy convencido, de hacer descender a Dios para convertir el vino y al pan en su cuerpo y en su sangre (Seminarista “7”, Seminario Mayor de Texcoco 2008).

En los siguientes testimonios se infiere el poder del cual goza esta masculinidad hegemónica, así mismo la manera en que ocupa exitosamente su autoridad: 
aparte de que es sacerdote, siempre cuenta con esa parte como que amiga, de que, a pesar de que tiene un rango o una jerarquía un poco más alta; siempre se encuentra al nivel (Seminarista "2", Seminario Mayor de Texcoco 2008).

La figura del sacerdote, para mi, en este etapa, me representa como el que tiene realmente que estar al servicio de la comunidad (Seminarista "10", Seminario Mayor de Texcoco 2008).

La comunidad también da muestras de esta hegemonía de la siguiente manera:

Pues que son, para empezar ellos son privilegiados, no todos tenemos este pues la bendición de Dios de ser elegidos, y pues sobre todo que son humanos, tienen errores igual que nosotros y que son este personas realmente, dedicadas a amar a Dios amar y a servirnos a nosotros [...] yo creo para orientarnos, para encandilarnos más al camino de la verdad, para ser mejores humanos, para poder este ser felices nosotros (Mujer adulta de San Francisco Mazapa, 2008).

Y en lo referente a la subordinación de las mujeres, no es necesario evidenciar con testimonios que la mujer no puede formarse para ordenarse como sacerdotisa, y en este sentido esta masculinidad hegemónica asegura la subordinación de la mujer.

\section{Poder y capacidad de mando}

Al continuar con uno de los atributos masculinos que conforman la masculinidad patriarcal según Daniel Cazés (1995), está el atributo de ejercer poder público y la capacidad de mandar, organizar. En las observaciones participantes realizadas en el trabajo de campo se notó que en el espacio donde los seminaristas realizan su trabajo pastoral ejercen y desarrollan el ejercicio del poder público y cómo las personas se lo confieren; de tal manera que se convierten en líderes desde su formación. El siguiente testimonio muestra cómo desde sus actividades pastorales descubren estos componentes: 
Bien, yo creo que mi carácter es para poder poner atención a muchas personas y a todos brindarles la solución que quieren, o darles la respuesta que quieren. Me siento muy bien, y más porque, me tomen en cuenta, que me tomen identificado como el líder de los que estás llevando (Seminarista “2”, Seminario Mayor de Texcoco 2008).

Las personas de la comunidad también perciben el liderazgo de los alumnos. Ante la pregunta ¿qué es lo que usted considera lo más importante que aporta el seminarista en el trabajo pastoral?, la gente responde de manera similar:

Lo más importante es que nos encaminan a ser felices y a conocer, que conozcamos más a Dios para que seamos felices en este reino de Dios que construimos nosotros [...] porque fijese que han dejado de venir un tiempo y el grupo juvenil se desbarata, los grupos de misión que tenemos allí dentro de la parroquia y todo, si se empiezan a retirar y cuando hay seminaristas o religiosas, otra vez se vuelven a juntar, vuelven a tomar, otra vez con más entusiasmo las actividades y ¿como no?, sí nos hacen falta (Mujer adulta de San Francisco Mazapa 2008).

Con tal componente, se refuerza la hegemonía de la masculinidad clerical.

\section{Prestigio}

En cuanto a este componente, en las entrevistas con los seminaristas se puede notar en primer momento que la actitud familiar suele modificarse casi siempre de manera favorable hacia el alumno y que la candidatura a sacerdocio, los coloca en un estatus privilegiado con relación a otros integrantes de la familia:

Y de hecho pues ahora que entré al introductorio, pues, yo ya los vi más emocionados, a mi mamá y a mi hermano, los vi desde el inicio, pero a mi papá fue el cambio [...] no sé, también lo vi a él más entusiasmado a comparación [...] ya lo ves y totalmente la reacción fue distinta (Seminarista “3”, Seminario Mayor de Texcoco 2008). 
En cuanto a la relación familiar me ven como una persona más madura [...] siempre como que ven que estoy interesado en ayudar a los demás, quieren que esté con mi familia, parientes, como que con las personas de la calle, como que con las personas de aquí, de acá, como que siempre ven así como que tengo mucha iniciativa, mis papás se sienten muy felices [...] entonces a ellos también es un orgullo, me presumen con mis tíos [...] y también otra parte porque me ven con sotana; tal vez para ellos es muy marcado el que uno de sus hijos está estudiando al sacerdocio, que en uno de sus hijos pueda tener este contacto con Dios, y a ellos los encamine a ese contacto con Dios, yo creo que también es algo muy padre que mi familia así como que lo ve muy fuerte (Seminarista "6", Seminario Mayor de Texcoco 2008).

Razones por las que algunos de ellos incluso toman las decisiones familiares por encima de la autoridad paterna y materna como se nota en el siguiente testimonio donde uno de los entrevistados se refiere a la relación con su hermano:

había veces que bueno, que realmente no lo soporto a veces por todo lo que hace ¿̨no?, todos los problemas que trae y bueno, creo que es el que le ha hecho un poquito más la vida de cuadritos a mi mamá. Si bueno, al grado que tiene poquito que me atreví a correrlo de la casa, y bueno, él se encuentra viviendo ahorita en Oaxaca (Seminarista “10”, Seminario Mayor de Texcoco 2008).

$\mathrm{Al}$ ser los seminaristas humanos elegidos por Dios, pues al elegir la formación sacerdotal, se dice que estos jóvenes "sintieron el llamado" adquieren también cierto prestigio ante las demás personas quienes los ven privilegiados por este hecho. "Yo digo que el ser seminarista pues es un privilegio porque es algo muy duro [...] es algo que no cualquiera, no cualquiera tiene esa dicha hasta para la misma familia, es en cierta forma una bendición" (Mujer adulta de Ecatzingo, México, 2008)

\section{Modelo que seguir por su comportamiento y conocimiento}

Este atributo se adquiere una vez que los seminaristas tienen el com- 
promiso de realizar actividades pastorales; pues, aunque en éstas su servicio no implique que impartan alguna cátedra, las personas con quienes interactúan, suelen depositarles la confianza para consultarles o para tomarlos como modelos a seguir. Los siguientes testimonios pertenecen a personas de las comunidades quienes hablan de su relación con el seminarista donde se percibe cómo sólo con el trato los seminaristas adquieren este rasgo:

Pues yo digo que muy bien porque él es muy buena persona, muy sencilla o sea noble, es pues si como que te sabe escuchar, o sea, cuando tienes un problema pues él te escucha, pues sí muy bueno (Mujer joven de Ecatzingo, Estado de México, 2008).

Pues muy bonita, muy buena, muy buena con mucha comunicación con él, todo lo que le preguntamos, pues éste nos trata de, de orientar lo más que se puede, sí es muy buena su comunicación (Mujer adulta de San Francisco Mazapa 2008).

Y con respecto a su labor pastoral se presentan los siguientes testimonios:

ellos también juegan un papel importante aunque no sean sacerdotes, porque también nos ayudan a nosotros a ir conociendo más cosas que no sabíamos; entonces pues, sí, es importante también ser seminarista (Mujer joven de Acolman 2008).

Salir, como dicen ellos buscar a las casas, o sea, buscar la gente que les quiera escuchar, porque de otra forma la gente no se arrima mucho a la iglesia por varios pretextos, en cambio ellos salen a buscar a las casas, sí logran hacer algo, convencer (Hombre adulto de Francisco Mazapa 2008).

Por otro lado, una de las misiones principales del servicio pastoral es "la evangelización inculturada" que se refiere a la inserción progresiva de la fe cristiana en la cultura de un pueblo. El seminario prepara a los alumnos para el servicio pastoral con dos objetivos: 1) que los alumnos desarrollen las aptitudes cristianas necesarias que sirvan como base y preparación para el ejercicio de promoción de 
fe; y 2) que se aprendan los principios y métodos para "enseñar, santificar y gobernar el Pueblo de Dios". ${ }^{2}$

Se les pide este servicio pastoral para que vayan conociendo más a fondo, cuáles son las necesidades de una comunidad pastoralmente, que también sepan cuáles son los conflictos que se dan en una parroquia [...] cómo se involucra el sacerdote en una comunidad y que también ellos se vayan aventurando a ser de alguna manera líderes o cabezas de ciertos grupos; que sepan hablar en público, que sepan moverse con todo tipo de personas, que sepan convivir con ellos porque también se les pide ir a vivir a casa de familias que voluntariamente se apuntan para hospedarles [...] yo creo que esto también les ayuda a los chicos, como que a descubrir qué es lo que la gente busca de la religión, qué es lo que busca de Dios [...] como también los muchachos que después de un año ya han tenido formación, también pueden ir a compartir algo acerca de lo que han experimentado de Dios y de la Iglesia como tal (Formador del Seminario Mayor de Texcoco 2008).

De esta manera los seminaristas se encargan de modelar el pensamiento de otras personas o sus actitudes y con esto van adquiriendo otro componente más de hegemonía: la cualidad de experto.

\section{Cualidad de experto}

En este componente (refiriéndonos a la cualidad de "experto en religión”) se encuentra que la manera en que se forman los futuros sacerdotes contempla los fundamentos teóricos para sustentar el servicio pastoral. La formación teórica y práctica ocupa ocho años en su proceso formativo.

En las observaciones participantes realizadas en campo se encontró que una de las actividades principales que realizan los seminaristas es formar grupos para impartirles lo que llaman "revisión de Biblia”, actividad que consiste en la exposición de temas de la Biblia

${ }^{2}$ Normas Básicas y Ordenamiento Básico de los Estudios para la Formación Sacerdotal en México, 1999. 
por parte del seminarista. Según un seminarista, esta actividad tiene como fin que la gente entienda y asimile los textos bíblicos en su vida cotidiana, es decir, que se comprenda lo que la Biblia dice para que la gente ponga en práctica las palabras que guiarán sus actividades diarias. ${ }^{3}$

En la revisión de Biblia, el seminarista da indicaciones de la parte que revisarán (por ejemplo: capítulo I, versículo del 1 al 12) y da una introducción breve al tema, luego, pide a alguien que lea el texto y una vez concluida la lectura, el seminarista se pone de pie y explica con sus propias palabras y su propio entendimiento, lo que el texto significa procurando dar ejemplos cotidianos.

Llama la atención que la actitud de las personas que escuchan la interpretación del seminarista es totalmente pasiva y receptiva, de modo que su participación es casi nula, no hay cuestionamientos, ni opiniones y no hay quien refute lo que el seminarista alecciona. Así, el seminarista es quien conoce, quien difunde y "quien tiene la verdad" en sus palabras, es el "experto".

Después de esta revisión notamos que la masculinidad clerical tiene dos características fundamentales: Primero: Los varones que deciden formarse como sacerdotes tienen una masculinidad con rasgos femeninos debido a que han adquirido un estilo de vida basado en lineamientos religiosos (masculinidad religiosa). Por otro lado, la formación sacerdotal obliga a desarrollar otras características comúnmente asociadas al rol femenino como lo es el servicio, la generosidad, la empatía, la fraternidad e incluso actividades domésticas.

Segundo: sin embargo, los rasgos asociados al rol femenino ya sea previamente adquiridos o desarrollados durante la formación sacerdotal, ni impiden el nacimiento de nuevas características que coinciden con la masculinidad hegemónica como lo son la hegemonía exclusiva del sacerdote como representante de Dios, el poder público y la capacidad de mando, el prestigio, el convertirse en modelo por seguir por su comportamiento y conocimientos y la cualidad de experto.

\footnotetext{
${ }^{3}$ Trabajo de campo en San Francisco Mazapa, Estado de México, 2008.
} 
Por lo tanto, la masculinidad clerical es aquella que se caracteriza por contener rasgos asociados con la feminidad social previamente adquiridos y desarrollados durante la formación sacerdotal, y por contener de manera conjunta rasgos asociados con la masculinidad hegemónica única otorgada por la Iglesia y por los feligreses.

\section{Conclusiones}

En general se tiene una percepción muy positiva de los varones que se involucran en actividades religiosas; sin embargo cuando estos jóvenes se convierten en seminaristas, su percepción se modifica otorgándoles el poder que conforma su masculinidad.

La masculinidad del seminarista, la edad, el lugar de procedencia, la escolaridad, el contexto familiar, económico, de salud, sexual, psicológico e intelectual, conjuntan una serie de características que describen una identidad masculina que surge debido a que los varones que se ven motivados a ingresar a la formación sacerdotal, viven en un sistema patriarcal, pero no cuentan con características propias de varones con poder patriarcal; aunque sí lo obtienen posteriormente durante su estancia en el seminario a través de la Iglesia misma y sobre todo por parte de la feligresía (especialmente mujeres).

Debido a lo anterior, los varones con características más asociadas al rol femenino, con carencia de poder y con la religión como guía para su estilo de vida, se perfilan con una masculinidad especial necesaria para ingresar a la formación sacerdotal (masculinidad religiosa), puesto que facilita las características femeninas que ha de inculcar el seminario una vez que ingresan.

La masculinidad religiosa se convierte en masculinidad clerical una vez que los jóvenes han ingresado a la formación sacerdotal; y, aunque la masculinidad clerical es el resultado de la masculinidad religiosa modelada por la formación sacerdotal, no necesariamente tendría que existir una masculinidad religiosa previamente para que se desarrolle una masculinidad clerical, puesto que algunos jóvenes ingresan a la formación sacerdotal sin las características femeninas que se encuentran implícitas en la masculinidad religiosa (sin embargo, son los menos). 
La formación sacerdotal inculca ciertos componentes que se oponen a la masculinidad tradicionalmente patriarcal, al tiempo que fundamenta y refuerza ciertas características asociadas con la masculinidad hegemónica.

El desarrollo de la masculinidad clerical resultaría fácilmente percibido como una paradoja puesto que implica dos características contrapuestas; sin embargo, no es una paradoja en sí misma, sino un proceso de transformación del poder. La masculinidad de los varones que deciden formarse como sacerdotes tienen una masculinidad con rasgos femeninos debido a que han adquirido un estilo de vida basado en lineamientos religiosos (masculinidad religiosa). Por otro lado, la formación sacerdotal obliga a desarrollar otras características comúnmente asociadas al rol femenino como lo es el servicio, la generosidad, la empatía, la fraternidad e incluso actividades domésticas, sin embargo, los rasgos asociados al rol femenino ya sea previamente adquiridos o desarrollados durante la formación sacerdotal, no impiden el nacimiento de nuevas características que coinciden con la masculinidad hegemónica como lo son la hegemonía exclusiva del sacerdote como representante de Dios, el poder público y la capacidad de mando, el prestigio, el convertirse en modelo por seguir por su comportamiento y conocimientos y la cualidad de experto.

Por último, podemos decir que la tipología de masculinidades mencionada no pretende homogeneizar las identidades de los seminaristas. Al contario, la diversidad de experiencias en campo mostró grados diferentes de aproximación a la tipología propuesta, sin embargo, consideramos que en términos teóricos es útil la definición de estos modelos para facilitar el análisis de las masculinidades y la religión.

\section{BIBLIOGRAFÍA}

Amuchástegui Herrera, Ana, "Masculinidad(es)?: los riesgos de una categoría en construcción" en Gloria Careaga y Salvador Cruz Sierra, coords., Debates sobre masculinidades. Poder, desarrollo, politicas públicas y ciudadanía, México, UnAm, Programa Universitario de Estudios de género, 2006, 159-181. 
Bonino, Luis, "Los varones ante el problema de la igualdad con las mujeres" en Lomas C., ed., ¿Todos los hombres son iguales? Identidad masculina y cambios sociales, Barcelona, Paidós, 2003. También en: http://www.luisbonino.com/pdf/Los\%20varones\%20 ante $\% 20$ el $\% 20$ problema $\% 20$ de $\% 20$ la $\%$ 20igualdad $\% 20$ con $\% 20 \% 201$ as\%20mujeres.pdf.

Bourdieu, Pierre, El baile de los solteros, Anagrama, 2004.

Briceño, Gustavo, El género también es asunto de hombres. Reflexiones sobre la masculinidad patriarcal y la construcción de una masculinidad con equidad de género, San José, Costa Rica, El Productor, R. L, 2001.

Brusco, Elizabeth E., The Reformation of Machismo. Evangelical Conversion and Gender in Colombia, University of Texas Press, 1995.

CAzÉs, Daniel, "La dimensión social de género: posibilidades de vida para mujeres y hombres en el patriarcado" en Antología de la sexualidad humana, tomo 1, México, Consejo Nacional de Población, 1995, 335-388.

Ceballos, Rita María, "La masculinidad machista y la masculinidad liberadora: El modelo de Jesús de Nazaret”, Revista Pasos, núm. 134, 2007, 1-11.

Connell, Robert, Masculinidades, México, unam, Programa Universitario de Estudios de Género, 2003.

Hernández, Óscar Misael, "Debates y aportes de los estudios sobre masculinidades en México", en Relaciones. Estudios de Historia y Sociedad, vol. xxIx, núm. 116, 2008.

Huerta, Rojas Fernando, El juego del hombre. Deporte y masculinidad entre obreros, México, Benemérita Universidad Autónoma de Puebla, Plaza y Valdés Editores, 1999.

Kaufman, Michael, "Las experiencias contradictorias del poder entre los hombres" en Teresa Valdés y José Olavarría, eds., Masculinidad/es. Poder y crisis, Chile, FLACso e Isis Internacional, Ediciones de las mujeres, 1993, 63-81.

Kimmel, Michael, "El desarrollo (de género) del subdesarrollo (de género). La producción simultánea de masculinidades hegemónicas y dependientes en Europa y Estados Unidos” en Teresa Valdés y José Olavarría, eds., Masculinidades y equidad 
de género en América Latina, Chile, Flasco y unfPa, 1988, 207-217.

"Homofobia, temor, vergüenza y silencio en la identidad masculina" en Teresa Valdés y José Olavarría, eds., Masculinidad/ es. Poder y crisis, Chile, FLACso e Isis Internacional, Ediciones de las mujeres, 1997, 49-62.

,"La masculinidad y la reticencia al cambio", Revista Letras, México, Periódico la Jornada, 1999, 8-9.

Lagarde, Marcela, Los cautiverios de las mujeres. Madresposas, presas, putas, monjas y locas, México, Coordinación General de Estudios de Posgrado, Facultad de Filosofía y Letras, unam, 1993.

Normas Básicas y Ordenamiento Básico de los Estudios para la Formación Sacerdotal en México, 1999.

Ramírez, Juan Carlos, “¿Y eso de las masculinidad?: Apuntes para una discusión" en Gloria Careaga y Salvador Cruz Sierra, coords., Debates sobre masculinidades. Poder, desarrollo, politicas públicas y ciudadania, México, unam, Programa Universitario de Estudios de género, 2006, 31-55.

Reyes, Francisco, Otra masculinidad posible. Aportes para una masculinidad humana y humanizadora. Un acercamiento biblico y teológico, Colombia, Dimensión Educativa, 2004.

TAmez, Elsa, Teólogos de la Liberación hablan sobre la mujer, San José, Costa Rica, Departamento Ecuménico de Investigación, 1988.

FECHA DE RECEPCIÓN DEL ARTículo: 6 de agosto de 2010 FECHA DE RECEPCIÓN DE LA VERSIÓN FINAL: 19 de mayo de 2011 